\title{
Optimal Ordering Policy and Coordination Mechanism of a Supply Chain with Controllable Lead-Time-Dependent Demand Forecast
}

\author{
Hua-Ming Song, ${ }^{1}$ Hui Yang, ${ }^{1}$ and Jian-Qiang Luo ${ }^{2}$ \\ ${ }^{1}$ Department of Management Science and Engineering, Nanjing University of Science and Technology, \\ Nanjing 210094, China \\ ${ }^{2}$ Department of Industrial Engineering, Jiangsu University, Zhenjiang 212013, China
}

Correspondence should be addressed to Hua-Ming Song, huaming@mail.njust.edu.cn

Received 8 November 2010; Revised 20 May 2011; Accepted 6 July 2011

Academic Editor: J. J. Judice

Copyright (c) 2011 Hua-Ming Song et al. This is an open access article distributed under the Creative Commons Attribution License, which permits unrestricted use, distribution, and reproduction in any medium, provided the original work is properly cited.

\begin{abstract}
This paper investigates the ordering decisions and coordination mechanism for a distributed shortlife-cycle supply chain. The objective is to maximize the whole supply chain's expected profit and meanwhile make the supply chain participants achieve a Pareto improvement. We treat lead time as a controllable variable, thus the demand forecast is dependent on lead time: the shorter lead time, the better forecast. Moreover, optimal decision-making models for lead time and order quantity are formulated and compared in the decentralized and centralized cases. Besides, a threeparameter contract is proposed to coordinate the supply chain and alleviate the double margin in the decentralized scenario. In addition, based on the analysis of the models, we develop an algorithmic procedure to find the optimal ordering decisions. Finally, a numerical example is also presented to illustrate the results.
\end{abstract}

\section{Introduction}

Along with the development of new technology, increasingly diversified customers' demand, and higher competition, the lifespan of some products are getting shorter and shorter (so are called short-life-cycle products). Short-life-cycle products, such as toys, sunglasses, hightechnology products, and fashion clothing, which are characterized by short sales season, high demand variety, and long replenishment lead time. In addition, for short-life-cycle products, both overstock and understock could result in huge loss, thus reducing demand uncertainty is the main task in managing this kind of supply chain (see Lowson et al. [1]).

In practice, $\mathrm{QR}$ (quick response) with forecast updates is a method for reducing demand uncertainty (see, e.g., Tersine and Hummingbird [2], Rohr and Correa [3], and Perry et al. [4]). Its idea is to cut ordering lead time and enable orders from retailers to be placed 
close to the start of the selling season. Through the postponement, information is gathered to update the demand forecast (see Iyer and Bergen [5]).

Concerning forecast updates, the Bayesian approach is a well-known technique to use new information to revise the demand forecast. The procedure of forecast updates using Bayesian approach is as follows. First, a demand distribution is chosen from a family of distributions whose parameters are partly or both stochastic with given prior distributions. Second, if new information becomes available, Bayesian formula is used to calculate posterior distributions of the parameters. Last, the posterior distributions of the parameters are used to update demand distribution.

When lead time can be shortened by extra investment (when it is controllable), there are two problems in ordering decision making. The first question is when to order and how much to order from the stand point of a buyer. This question involves two tradeoffs: longer versus shorter lead time, more versus less ordering quantity. A shorter lead time leads to lower demand uncertainty, more crashing cost, and vice versa. On the other hand, the more ordering quantity results in less cost of understock, more cost of overstock, and vice versa. The second question is how to motivate the supply chain participants to cooperate and achieve a win-win situation with contract from the stand point of the supply chain. This is because decisions made from the perspective of the whole supply chain may not always make both supply chain participants better off.

Lead time is an important factor that affects the operational cost, service level and forecast uncertainty in a short-life-cycle-product supply chain. However, most of the literatures on short-life-cycle products focused on how much to order (decision on ordering quantity) and neglected the decision on when to order (decision on lead time). Because of the complexity of the decision based on both the lead time and ordering quantity, the optimal ordering policy for short-life-cycle products with controllable lead time has not been fully studied.

The purpose of this paper is to take lead time decision making into account in a distribution supply chain, which consists of one retailer and one manufacturer. The supply chain operates a single short-life-cycle product. Optimal ordering policies with lead time decision in two scenarios are considered. In the decentralized decision-making scenario, the retailer makes decisions on lead time and ordering quantity to maximize his own profit. In the centralized decision scenario, decisions on lead time and ordering quantity are made to maximize the whole supply chain's profit. In addition, a supply chain contract is developed to coordinate the supply chain, and the conditions that the supply chain contract works are investigated.

The remainder of the paper is organized as follows. Section 2 briefly reviews the related literatures. Section 3 gives some notations and basic assumptions of the research topic. Then, in Section 4, a decentralized decision-making model to maximize the retailer's profit and a centralized decision-making model to maximize the system-wide supply chain's profit are formulated. Furthermore, we discuss the existence and attributes of the optimal solutions, and efficient algorithms to search the optimal solutions are developed. In Section 5, a threeparameter supply contract is proposed, and the conditions needed for successful coordination are investigated. The numerical analysis is carried out in Section 6. The paper is concluded in Section 7.

\section{The Literature Review}

There are three categories of literature related to our research. The first is on QR policy with forecast updates, the second is on inventory management with controllable lead 
time, and the third is on supply coordination with contracts. We briefly review them, respectively.

\subsection{The Literatures on QR with Forecast Updates}

This kind of the literature utilizes the Bayesian theorem to update forecast for short-life-cycle products, which is the same as our work. However, the literature focuses on the concept of lead time reduction other than decision on lead time. In addition, the cost of lead time reduction and the relationship between lead time and forecast error have not been clearly considered. In this section, we review some of the works especially related to our study.

Among them, Iyer and Bergen [5] investigate the effects of QR on supply chain participants. They observe that cutting lead time is always beneficial to the retailer while harmful to the vendor when the service level is more than 0.5. However, only ordering quantity decision is involved in their works, and there is no tradeoff between the benefits and the cost of lead time reduction in their model. Otherwise, if the cost of lead time reduction is considered, their conclusion will change.

$\mathrm{Wu}$ [6] extends Iyer and Bergen's [5] forecast updates mode from a single stage to multiple stages and proposes a flexible contract to coordinate the supply chain. Similarly, lead time decision is not included in Wu's [6] work. From the numerical examples in [6], it is shown that more stages of forecast updates leads to more profits of the whole supply chain participants. It is obvious that this is not the truth if the cost of forecast updates or the cost of lead time reduction is considered.

Similarly, without concerning crashing cost, Choi [7] extend Iyer and Bergen's [5] work to a scenario that new information can be used to update both the unknown mean and unknown variance for the short-life-cycle product's demand. Choi [7] conclude that the QR policy is always beneficial to the retailer and not necessarily beneficial to the supplier when the service level is more than 0.5 (this conclusion is similar to that of Iyer and Bergen [5]). Here, we can say that if the cost of lead time reduction is considered, we can get a different conclusion. Further, Choi et al. [8] takes dual updates and costs uncertainty and differences into account in his work, but there is no explicit relationship between the forecast error and lead time. Meanwhile, lead time decision is not taken into account in their models.

Fisher and Raman [9], Gurnani and Tang [10], Donohue [11], Sethi et al. [12], Choi and Li [13], Choi [14], Chen et al. [15], and Chen et al. [16] study the optimal ordering policy with two ordering opportunities. The unit cost at the second stage may be higher than that at the first stage (see, Fisher and Raman [9], Donohue [11]) or may be uncertain (see, Gurnani and Tang [10], Sethi et al. [12], Choi and Li [13], Choi [14]Chen et al. [15]). In these works, the retailer makes decisions on the two sequent ordering quantities by evaluating the tradeoff between a more accurate forecast and a potentially higher unit cost at the second stage. There is no explicit relationship between the forecast error and lead time. Meanwhile, lead time decision is not taken into account in their models.

Similarly, Sethi et al. [17-19] extend ordering policy from two periods to multiple periods. In each period, decisions on how much to order using some given delivery modes are made. However, lead time decisions and the relationship between lead time and forecast error are not involved in their works.

The research of the paper is very similar to that of Choi et al. [20], which investigates a retailer's optimal single ordering policy with multiple delivery modes. But our model differs from theirs in two major aspects. Firstly, in our paper, lead time is a decision variable. Both the forecast error of expected demand and the crashing cost are functions of the lead time. 
The decision making on lead time is to make tradeoff between the crashing cost and benefits of forecast improvement. However, lead time decision isn't involved in their model. Secondly, a three-parameter risk-sharing supply contract is proposed to coordinate the decentralized supply chain, and the conditions of channel coordination are derived in our paper, while their work is only related to the optimal ordering decision from the standpoint of the retailer.

This research explicitly takes the relationship between lead time and the forecast error, the relationship between lead time and crashing cost, into account, simultaneously addressing the two problems mentioned in Section 1 in a distribution supply chain.

\subsection{The Literatures on Variable or Controllable Lead Time}

The literature falling into this category mainly focus on ordering quantity, lead time, service level, and so forth. The treatment of lead time as a deterministic decision variable within inventory models began with Liao and Shyu [21]. They introduced the concept of crashing cost to stochastic inventory models, in which lead time can be decomposed into $n$ components, and each has an independent crashing cost for reduced lead time. Sequentially, many researchers have developed various analytical inventory models to extend Liao and Shyu's [21] model (see, e.g., Ben-Daya and Raouf [22], Ben-Daya and Hariga [23], Ouyang et al. [24-27], Moon and Choi [28], Moon and Cha [29], Hariga and Ben-Daya [30], Hariga [31], Pan and Yang [32], C. Chang and S. Chang [33], Chang et al. [34, 35], Chu et al. [36], Lee et al. [37], Lin [38], Wu et al. [39], and Jha and Shankera [40]).

This paper is similar to the above-mentioned literatures with the concept that lead time is a decision variable and can be reduced at an added crashing cost. However, there are three differences between this paper and the above-mentioned studies. Firstly, the abovementioned studies dealt with multiperiod inventory problems for durable goods; this paper dealt with single-period ordering problem for short-life-cycle products, whose demands have high uncertainty. Secondly, neither the relationship between lead time and the forecast error nor forecast updates are taken into account in the above-mentioned studies. Thirdly, the above-mentioned literature investigated an optimal decision from a stand point of the single supply chain participant or from a standpoint of the whole supply chain, and the coordination was not considered.

\subsection{The Literatures on Supply Chain Coordination with Contract}

Due to the conflicts of interests and the distributed nature of the decision structure in supply chain, there exists double marginalization (Spengler [41]) that may lead to low efficiency in supply chain. Among various kinds of supply chain coordination, the coordination by contract received much attention. Hennet and Arda [42] evaluate the efficiency of different types of contracts between the industrial partners of a supply chain. Cachon [43] makes a comprehensive review of supply chain contracts. In the literature, various contracts are developed to coordinate the supply chain, such as buyback contract (Padmanabhan and Png [44]), quantity flexibility contract (Tsay [45]), revenue-sharing contract (Cachon and Lariviere [46]), and wholesale price only contract (Lariviere and Porteus [47]).

Each kind of contract has its limitations and strengths as Arshinder et al. [48] point out that the study of supply chain coordination is still in its infancy, and a little effort has been reported in the literature to develop a holistic view of coordination.

In fact, to develop a contract needs to orient the specific problem and the potential risk. In our work, the retailer's decisions onlead time and ordering quantity can bring 
crashing cost, overstock loss, or understock loss. Neither single contract above mentioned can coordinate the two risks. Therefore, we develop a three-parameter supply contract to coordinate these risks simultaneously. Further, the contract can flexibly allocate the profit of the supply chain according to the participants' value-added capabilities, and it is easy for practitioners to adopt in practice.

\section{Notations and Assumptions}

We will begin the modeling process by presenting the following notations and assumptions.

\subsection{Notations}

The notations employed in the paper are as follows:

$p$ : unit retail price of the retailer,

$v$ : unit residual value of the unsold product of the retailer,

$c$ : unit product cost of the manufacturer,

$n$ : numbers of mutually independent lead-time components,

$o_{j}$ : crashing cost when one unit time is shorten for the $j$ th $(1 \leq j \leq n)$ lead-time component,

$a_{j}$ : minimum time of the $j$ th $(1 \leq j \leq n)$ lead-time component,

$b_{j}$ : regular time for the $j$ th $(1 \leq j \leq n)$ lead-time component,

$w_{0}$ : unit wholesale price which the manufacturer provided to the retailer, $p>w_{0}>$ $c>v$,

$q$ : ordering quantity from the retailer (decision variable for the retailer),

$t$ : lead time (decision variable for the retailer); it is the time from the retailer placing an order to receiving goods and using this goods to meet the end consumers' demand. It can be changed by adding an extra investment. The longest lead time is $T_{n}$, and the shortest is $T_{0}$,

$X$ : market demand; it is a stochastic variable, mean of $X$ is also a stochastic variable,

$f_{X}(\cdot)$ : probability distribution function (pdf) of the stochastic variable $X$,

$f_{X \mid Y}(\cdot)$ : conditional pdf of the stochastic variable $X$ given $Y$,

$\Phi(\cdot)$ : cumulative distribution function (cdf) of standard normal distribution,

$\varphi(\cdot)$ : pdf of standard normal distribution,

$X^{+}$: maximum value of $X$ and 0 , that is; $X^{+}=\max \{X, 0\}$,

$E(\cdot)$ : mathematical expectation of a stochastic variable.

\subsection{Assumptions}

The assumptions employed in this paper are stated as follows. 


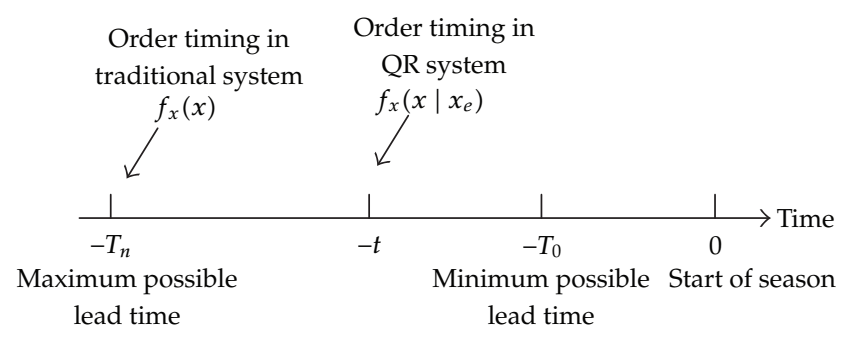

Figure 1: Process of demand forecast updates.

\section{(1) Assumption about the Supply Chain and Its Participants}

A single-buyer-single-vendor supply chain that manufactures and sells a single short-lifecycle product. The retailer and the manufacturer are both risk neutral. Viewing the wholesale price as a given parameter, the retailer makes decisions on when to order and how many to order. This paper assumes that the retailer only has one ordering opportunity in the entire selling season, which is based on long replenishment lead time and other situations (see, Choi et al. [20]).

\section{(2) Assumption about the Lead Time}

For the sake of simplicity, we assume that the selling season begins at time zero, see Figure 1. Therefore, " $-t$ " refers to $t$ time units ahead. The minimum time of the $j$ th $(1 \leq j \leq n)$ component of lead time is $a_{j}$; regular time is $b_{j}$; crashing cost per unit time is $o_{j}$.

To facilitate our discussion, $n$ mutually independent components of lead time are realigned according to the unit crash costs in a descending order, denoted by $o_{1} \geq o_{2} \geq \cdots \geq$ $o_{n}$. The component of the smallest per unit crashing costs should be prioritized when lead time is reduced; the rest may be deduced by analogy.

The maximum lead time, all whose components are equal to regular time, is denoted by

$$
T_{n}=\sum_{j=1}^{n} b_{j}
$$

The minimum lead time, all whose components are equal to the minimum time, is denoted by

$$
T_{0}=\sum_{j=1}^{n} a_{j}
$$

If the components from 1 to $i$ all have the regular lead time, the others (from $i+1$ to $n$ ) have a minimum time, then the lead time is

$$
T_{i}=\sum_{j=i+1}^{n} a_{j}+\sum_{j=1}^{i} b_{j}, \quad i=1,2, \ldots, n
$$


It is easy to know that

$$
T_{i}=\sum_{j=1}^{n} b_{j}-\sum_{j=i+1}^{n}\left(b_{j}-a_{j}\right), \quad i=1,2, \ldots, n .
$$

Given lead time $t\left(T_{0} \leq t \leq T_{n}\right)$, the total crashing cost is

$$
R(t)= \begin{cases}o_{1}\left(T_{1}-t\right)+\sum_{j=2}^{n} o_{j}\left(b_{j}-a_{j}\right), & T_{0} \leq t<T_{1} \\ o_{2}\left(T_{2}-t\right)+\sum_{j=3}^{n} o_{j}\left(b_{j}-a_{j}\right), & T_{1} \leq t<T_{2} \\ \vdots & \\ o_{i}\left(T_{i}-t\right)+\sum_{j=i+1}^{n} o_{j}\left(b_{j}-a_{j}\right), & T_{i-1} \leq t<T_{i} \\ \vdots & \\ o_{n}\left(T_{n-1}-t\right), & T_{n-1} \leq t \leq T_{n} .\end{cases}
$$

\section{(3) Assumption about the Information Updates}

In this paper, we extend the demand uncertainty structure in Iyer and Bergen [5]. Demand uncertainty has two levels, and it is related to lead time $t$. The first source of uncertainty concerns the expected demand during the selling season; $\Theta$ is a stochastic variable and has pdf: $f_{\Theta}(\theta) \sim N\left(\mu, \tau^{2}\right)$. This is called the prior pdf of the expected demand. Given the value of the expected demand, $\Theta=\theta$, the demand for product during the selling season is also a stochastic variable, and the forecast error is denoted by $s(t)$. The demand $X$ during the selling season has pdf: $f_{X \mid \Theta}(x \mid \theta) \sim N\left(\theta, s^{2}(t)\right)$. Thus, the pdf for $X$ is

$$
f_{X}(x)=\int_{\theta} f_{X \mid \theta}(x \mid \theta) f_{\theta}(\theta) d \theta \sim N\left(\mu, s^{2}(t)+\tau^{2}\right) .
$$

In the traditional system, the order is placed at time $T_{n}$, and there are no information updates. Thus, at the time $T_{n}$, the pdf for demand $X$ is

$$
\int_{\theta} f_{X \mid \theta}(x \mid \theta) f_{\theta}(\theta) d \theta \sim N\left(\mu, s^{2}\left(T_{0}\right)+\tau^{2}\right)
$$

In a QR system, an order is placed at time $t$, the demand information of related or similar products is observed, and the information is converted into a value, denoted by $x_{e}$, for the demand for the concerned product. This $x_{e}$ can be used to generate a posterior 


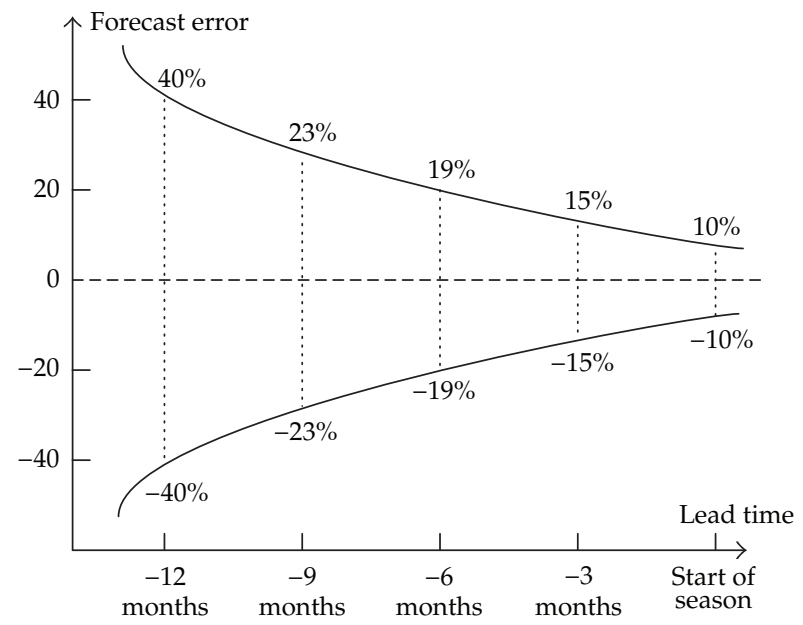

Figure 2: Relationship between the lead time and the forecast error of the expected demand (see Lowson et al. [1]).

distribution for expected demand. Utilizing Bayesian theorem to revise the forecast, we can get that

$$
f_{\Theta}\left(\theta \mid x_{e}\right)=\frac{f_{X \mid \Theta}\left(x_{e} \mid \theta\right) f_{\Theta}(\theta)}{\int_{\Theta} f_{X \mid \Theta}\left(x_{e} \mid \theta\right) f_{\Theta}(\theta) d \theta} \sim N\left(\frac{s^{2}(t) \mu+\tau^{2} x_{e}}{s^{2}(t)+\tau^{2}},\left(\frac{1}{s^{2}(t)}+\frac{1}{\tau^{2}}\right)^{-1}\right) .
$$

Thus, the pdf for $X$ can be further updated as follows:

$$
f_{X}\left(x \mid x_{e}\right)=\int_{\Theta} f_{X \mid \Theta}(x \mid \theta) f_{\Theta}\left(\theta \mid x_{e}\right) d \theta \sim N\left(\frac{s^{2}(t) \mu+\tau^{2} x_{e}}{s^{2}(t)+\tau^{2}}, s^{2}(t)+\left(\frac{1}{s^{2}(t)}+\frac{1}{\tau^{2}}\right)^{-1}\right) .
$$

This update can be shown in Figure 1.

\section{(4) Assumption about the Forecast Error of the Expected Demand}

The essential benefit from $Q R$ for fashion products is that the information gathered regarding the sales of related items can be used to reduce forecast error of the expected demand. The magnitude of this reduction in forecast error can be substantial (see, Iyer and Burger [5]). As pointed out by Blackburn [49], there is a fundamental principle of forecasting: the shorter the lead time, the better the forecast. According to Lowson et al. [1] and Blackburn [49], in fashion or seasonal apparel industrial, if lead time is cut down from 12 months to 6 months, the forecast error decreases from \pm 40 percent to \pm 19 percent. In addition, the forecast error grows more than linearly as the time to forecast increase, forming a familiar shape known to forecasters as "trumpet of doom." It can be seen from Figure 2 that there is a direct relationship between lead time (i.e., time ahead of a sales season) and demand forecast error. If the order decision is made at the start of the season, that is, the lead time approaches zero, the forecast error decreases down to \pm 10 percent. 
Let $s$ and $t$ denote the forecast error of the expected demand and lead time, respectively. We can fit the given observation data in Figure 2 to get the relationship between $s$ and $t$. In Appendix 7, it is shown that the nonlinear relationship between $s$ and $t$ can be written as

$$
s=\alpha e^{\beta t}
$$

Here, parameters $\alpha(>0)$ and $\beta(>0)$ may be estimated using the given data.

\section{Mathematical Models, Analysis, and Algorithms}

In this section, a decentralized decision-making scenario to maximize the retailer's profit and an integrated decision-making scenario to maximize the system-wide supply chain's profit are formulated. Furthermore, we discuss the existence and attributes of the optimal solutions to the above-mentioned models and develop the efficient algorithms to find the optimal solutions.

\subsection{Mathematical Models}

Under the assumptions in Section 3, if the retailer places his order at time $t\left(T_{0} \leq t \leq T_{n}\right)$, the pdf of demand forecasted can be written as (3.9). Once given the demand distribution at time $t\left(T_{0} \leq t \leq T_{n}\right)$, we can formulate the profits of the retailer, the manufacturer, and the whole supply chain.

If the market demand and ordering quantity are $X$ and $q$, respectively, we can get that the sales of the retailer will be $\min (q, X)$. Accordingly, the sales income will be $p \min (q, X)$ in the entire selling season. The unsold for the retailer after the selling season will be $(q-X)^{+}$, and the residual value of unsold goods is $v(q-X)^{+}$. Thus, given lead time $t\left(T_{0} \leq t \leq T_{n}\right)$, the expected profit of the retailer is

$$
\Pi_{r}(q, t)=\int_{x_{e}}\left[p E\left(\min \left(q, X \mid x_{e}\right)\right)+v E\left(q-X \mid x_{e}\right)^{+}-w_{0} q-R(t)\right] f_{x_{e}}\left(x_{e}\right) d x_{e} .
$$

Simplifying (4.1) by the integral operation, we can get the expected profit of the supply chain participants as follows.

The expected profit of the retailer is

$$
\Pi_{r}(q, t)=p E(\min (q, X))+v E(q-X)^{+}-w_{0} q-R(t) .
$$

The expected profit of the manufacturer is

$$
\Pi_{m}=\left(w_{0}-c\right) q
$$

The expected profit of the whole supply chain is

$$
\Pi_{l}(q, t)=\Pi_{r}(q, t)+\Pi_{m}=p E(\min (q, X))+v E(q-X)^{+}-c q-R(t),
$$


where $q, t$ satisfies the constraints that

$$
q>0, \quad T_{0} \leq t \leq T_{n} .
$$

Thus, the decision-making model from the view of the retailer is as follows. Model (I):

$$
\begin{aligned}
\max _{q, t} & \Pi_{r}(q, t)=p E(\min (q, X))+v E(q-X)^{+}-w_{0} q-R(t) . \\
\text { s.t. } & q>0, \quad T_{0} \leq t \leq T_{n} .
\end{aligned}
$$

The optimal solution of Model (I) is denoted by $\left(q^{D}, t^{D}\right)$.

In order to illustrate the effects of different decision-making scenarios on the profits of the supply chain participants and the whole supply chain, we assume that there would exist a virtual center whose decision objective is to maximize the profit of the whole supply chain channel. We call this situation as a centralized decision-making scenario and denote it as model (II).

Model (II):

$$
\begin{aligned}
\max _{q, t} & \Pi_{l}(q, t)=p E(\min (q, X))+v E(q-X)^{+}-c q-R(t), \\
\text { s.t. } & q>0, \quad T_{0} \leq t \leq T_{n} .
\end{aligned}
$$

The optimal solution to the model (II) is written as $\left(q^{I}, t^{I}\right)$.

\subsection{Model Analysis}

In order to solve the model (I) and model (II), some analysis needs to be done firstly. Since the two models are similar, we only analyze model (I). As far as model (II) is concerned, it may be deduced by analogy. For Model (I), we have the following conclusions.

Theorem 4.1. Denote the standard variance of demand after updates as $\sigma(t)$, then both $\sigma(t)$ and $d \sigma(t) / d t$ are increasing functions of lead time $t$.

Proof. For the sake of simplicity, $\sigma(t)$ and $s(t)$ are denoted by $\sigma$ and $s$, respectively. According to (3.9), the variance of demand after updates at a given lead time $t\left(T_{0} \leq t \leq T_{n}\right)$ can be expressed as

$$
\sigma^{2}=s^{2}+\frac{s^{2} \tau^{2}}{s^{2}+\tau^{2}}
$$

For the sake of simplicity, denote

$$
u=\frac{\tau^{2}}{s^{2}+\tau^{2}}
$$


It is obvious that $0<u<1$. Substituting (4.9) into (4.8), we can get

$$
\sigma^{2}=s^{2}(1+u)
$$

Taking the first derivative of $u$ with respect to $t$ and simplifying it through (3.10), we can obtain

$$
\frac{d u}{d t}=-2 \beta u(1-u)
$$

Taking the first derivative of $\sigma^{2}$ with respect to $t$ and simplifying it through (4.9), we can obtain

$$
\frac{d \sigma}{d t}=\frac{\beta s^{2}}{\sigma}\left(1+u^{2}\right)>0
$$

Taking the second derivative of $\sigma$ with respect to $t$ and simplifying it through (4.9), we can obtain

$$
\frac{d^{2} \sigma}{d t^{2}}=\frac{\beta^{2} s^{4}}{\sigma^{3}}\left(1+2 u-4 u^{2}+2 u^{3}+3 u^{4}\right)
$$

Simplifying (4.13) by factorization technique, we can get

$$
\left.\frac{d^{2} \sigma}{d t^{2}}=\frac{\beta^{2} s^{4}}{\sigma^{3}}\left[1+2 u(1-u)^{2}+3 u^{4}\right)\right]>0 .
$$

It is clearly seen that both $\sigma(t)$ and $d \sigma(t) / d t$ are increasing functions of lead time $t$ from (4.12) and (4.14).

Theorem 4.2. For fixed $t, \Pi_{r}(q, t)$ is a strictly concave function of $q$, and its maximal value occurs at $q=\mu+\sigma \Phi^{-1}\left(p-w_{0}\right) /(p-v)$. For $q=\mu+\sigma \Phi^{-1}\left(p-w_{0}\right) /(p-v), d / d t\left(\left.\Pi_{r}(q, t)\right|_{q=\mu+\sigma \Phi^{-1}\left(p-w_{0}\right) /(p-v)}\right)$ is a strictly decreasing function of $t$.

Proof. Two identical equations used are presented as follows.

$$
\begin{gathered}
\min (q, X)=X-(X-q)^{+}, \\
(q-X)^{+}=(q-X)+(X-q)^{+} .
\end{gathered}
$$

Insert (4.15) into (4.2), we can get

$$
\Pi_{r}(q, t)=p E\left(X-(X-q)^{+}\right)+v E\left((q-X)+(X-q)^{+}\right)-w_{0} q-R(t) .
$$


Further,

$$
\begin{gathered}
E\left(X-(X-q)^{+}\right)=E(X)-E(X-q)^{+}=\mu-E(X-q)^{+}, \\
E\left((q-X)+(X-q)^{+}\right)=q-E(X)+E(X-q)^{+}=q-\mu+E(X-q)^{+} .
\end{gathered}
$$

Insert (4.17) into (4.2), we can get

$$
\Pi_{r}(q, t)=(p-v) \mu-\left(w_{0}-v\right) q-(p-v) E(X-q)^{+} .
$$

Further, by integral operation, we can get

$$
E(X-q)^{+}=\int_{q}^{\infty}(x-q) f(x) \mathrm{d} x=\sigma\left(\varphi\left(\frac{q-\mu}{\sigma}\right)-\left(\frac{q-\mu}{\sigma}\right)\left(1-\Phi\left(\frac{q-\mu}{\sigma}\right)\right)\right) .
$$

Insert (4.19) into (4.18), and, by some algebraic operation, we can get

$$
\Pi_{r}(q, t)=\left(p-w_{0}\right) q-(p-v)\left[(q-\mu) \Phi\left(\frac{q-\mu}{\sigma}\right)+\sigma \varphi\left(\frac{q-\mu}{\sigma}\right)\right]-R(t) .
$$

Taking the first partial derivatives of $\Pi_{r}(q, t)$ with respect to $q$ and $t$; respectively, via (4.20), we can obtain

$$
\begin{gathered}
\frac{\partial \Pi_{r}(q, t)}{\partial q}=\left(p-w_{0}\right)-(p-v) \Phi\left(\frac{q-\mu}{\sigma}\right), \\
\frac{\partial \Pi_{r}(q, t)}{\partial t}=-(p-v) \varphi\left(\frac{q-\mu}{\sigma}\right) \frac{\partial \sigma}{\partial t}-\frac{\partial R}{\partial t} .
\end{gathered}
$$

Taking the second partial derivative of $\Pi_{r}(q, t)$ with respect to $q$ and $t$, we can obtain

$$
\frac{\partial^{2} \Pi_{r}(q, t)}{\partial q^{2}}=-(p-v) \varphi\left(\frac{q-\mu}{\sigma}\right)<0
$$

Setting the RHS of (4.21) to zero, we can get

$$
q=\mu+\sigma \Phi^{-1}\left(\frac{p-w_{0}}{p-v}\right)
$$

It is clearly seen from (4.23) that, for fixed $t, \Pi_{r}(q, t)$ is a strictly concave function of $q$. Therefore, for fixed $t$, the maximal value of $\Pi_{r}(q, t)$ occurs at $q=\mu+\sigma \Phi^{-1}\left(p-w_{0}\right) /(p-v)$. Given $p, w_{0}, v, \Phi^{-1}\left(p-w_{0}\right) /(p-v)$ is a constant.

Denote $k=\Phi^{-1}\left(p-w_{0}\right) /(p-v)$, then (4.24) can be written as follows:

$$
q=\mu+k \sigma
$$


Substituting (4.25) into (4.22), we can get

$$
\frac{d}{d t}\left(\left.\Pi_{r}(q, t)\right|_{q=\mu+k \sigma)}\right)=-(p-v) \varphi(k) \frac{d \sigma}{d t}-\frac{d R}{d t} .
$$

From (4.23), we can see that there is no variable $q$ in the expression of $d$ / $d t\left(\left.\Pi_{r}(q, t)\right|_{q=\mu+k \sigma)}\right)$. For convenience, we denote $g(t)=d / d t\left(\left.\Pi_{r}(q, t)\right|_{q=\mu+k \sigma)}\right)$.

Taking the partial derivative of $g(t)$ with respect to $t$ through (4.26), we can obtain

$$
\frac{d g(t)}{d t}=-(p-v) \varphi(k) \frac{d^{2} \sigma}{d t^{2}}
$$

According to Theorem 4.1, it is easy to know that $d g(t) / d t<0$. Therefore, $g(t)$ is a strictly decreasing function of $t$.

Theorem 4.3. The optimal solution to model (I) is in existence and unique.

Proof. For fixed $q$ in (4.21), take the partial derivative of $\partial \Pi_{r}(q, t) / \partial q$; with respect to $t$, we can obtain

$$
\frac{\partial^{2} \Pi_{r}(q, t)}{\partial q \partial t}=\frac{p-v}{\sigma} \frac{q-\mu}{\sigma} \varphi\left(\frac{q-\mu}{\sigma}\right) \frac{\partial \sigma}{\partial t} .
$$

Therefore, the Hessian Matrix of $\Pi_{r}(q, t)$ is as follows.

$$
H=\left[\begin{array}{cc}
-(p-v) \varphi\left(\frac{q-\mu}{\sigma}\right) & \frac{p-v}{\sigma} \frac{q-\mu}{\sigma} \varphi\left(\frac{q-\mu}{\sigma}\right) \frac{\partial \sigma}{\partial t} \\
\frac{p-v}{\sigma} \frac{q-\mu}{\sigma} \varphi\left(\frac{q-\mu}{\sigma}\right) \frac{\partial \sigma}{\partial t} & -(p-v) \varphi\left(\frac{q-\mu}{\sigma}\right)\left[\frac{(q-\mu)^{2}}{\sigma^{3}}\left(\frac{\partial \sigma}{\partial t}\right)^{2}+\frac{\partial^{2} \sigma}{\partial t^{2}}\right]
\end{array}\right] .
$$

Then, we proceed by evaluating the principal minor determinants of $H$. The first-order principal minor determinant of $H$ is

$$
H_{11}=-(p-v) \varphi\left(\frac{q-\mu}{\sigma}\right)<0 .
$$

The second-order principal minor determinant of $H$ is

$$
\begin{aligned}
H_{22} & =\left|\begin{array}{cc}
-(p-v) \varphi\left(\frac{q-\mu}{\sigma}\right) & \frac{p-v}{\sigma} \frac{q-\mu}{\sigma} \varphi\left(\frac{q-\mu}{\sigma}\right) \frac{\partial \sigma}{\partial t} \\
\frac{p-v}{\sigma} \frac{q-\mu}{\sigma} \varphi\left(\frac{q-\mu}{\sigma}\right) \frac{\partial \sigma}{\partial t} & -(p-v) \varphi\left(\frac{q-\mu}{\sigma}\right)\left[\frac{(q-\mu)^{2}}{\sigma^{3}}\left(\frac{\partial \sigma}{\partial t}\right)^{2}+\frac{\partial^{2} \sigma}{\partial t^{2}}\right]
\end{array}\right| \\
& =\frac{(p-v)^{2}}{\sigma} \varphi^{2}\left(\frac{q-\mu}{\sigma}\right) \frac{\partial^{2} \sigma}{\partial t^{2}}>0 .
\end{aligned}
$$


Thus, $H$ is a negative definite matrix. It is clearly seen that $\Pi_{r}(q, t)$ is a strictly concave function of $q$ and $t$. Thus, the maximum value of $\Pi_{r}(q, t)$ is in existence and unique.

Since Model (I) is similar to Model (II), we analyze the Model (I) only. From Theorem 4.2, if $\left(q^{D}, t^{D}\right)$ is the optimal solution to Model (I), then the condition, $q^{D}=$ $\mu+\sigma\left(t^{D}\right) \Phi^{-1}\left(p-w_{0}\right) /(p-v)$, must be satisfied. Therefore, how to get the optimal $t^{D}$ to the Model (I) is a key step in solving the Model (I). For Model (I), we have the following conclusion.

Theorem 4.4. The optimal $t^{D}$ to the Model (I) is the only one of the following four cases.

The optimal $t^{D}$ to the Model (I) is the only one of the following four cases.

Case 1. $t^{D}$ is $T_{0}$.

Case 2. $t^{D}$ is $T_{n}$.

Case 3. $t^{D}$ is the only one of the $T_{1}, T_{2}, \ldots, T_{n-1}$.

Case 4. $t^{D}$ is the only one solution to the equation $g(t)=0$ in a certain interval $\left(T_{i-1}, T_{i}\right), 2 \leq$ $i \leq n-1$.

Proof. If $\left.g(t)\right|_{t=T_{0}} \leq 0$, then, from Theorem 4.2, we can get that, for $t \in\left[T_{0}, T_{n}\right], g(t) \leq 0$. In this case, the optimal $t^{D}$ to the Model (I) is $T_{0}$, and this is Case 1.

If $\left.g(t)\right|_{t=T_{n}} \geq 0$, then, from Theorem 4.2, we can get that for $t \in\left[T_{0}, T_{n}\right], g(t) \geq 0$. In this case, the optimal $t^{D}$ to the Model (I) is $T_{n}$, and this is the Case 2.

Since $R(t)$ is defined in the interval $\left[T_{i-1}, T_{i}\right), i=1,2, \ldots, n-1$, and $g(t)$ is a continuous function of $t$ in the interval $\left[T_{i-1}, T_{i}\right), i=1,2, \ldots, n$, but not a continuous function of $t$ in the interval $\left[T_{0}, T_{n}\right]$, we denote $\left.g(t)\right|_{t=T_{i}^{-}}=\lim _{t \rightarrow T_{i}^{-}} g(t), i=1,2, \ldots n-1$. Then from Theorem 4.2, it is easy to know that $\left.g(t)\right|_{t=T_{i}^{-}}>\left.g(t)\right|_{t=T_{i}}$.

If $\left.g(t)\right|_{t=T_{n}}<0$ and $\left.g(t)\right|_{t=T_{0}}>0$, then from the Theorem 4.2, we know that there will exist a unique $i(1 \leq i \leq n)$, which satisfies that

$$
\left.g(t)\right|_{t=T_{i}^{-}} \geq 0,\left.\quad g(t)\right|_{t=T_{i}} \leq 0
$$

or

$$
\left.g(t)\right|_{t=T_{i-1}}>0,\left.\quad g(t)\right|_{t=T_{i}^{-}}<0 .
$$

If $\left.g(t)\right|_{t=T_{n}}<0$ and $\left.g(t)\right|_{t=T_{0}}>0$ and condition (4.32) is met, then from Theorem 4.2 we know that, for $t \in\left[T_{0}, T_{i}\right), g(t)>0$ and, for $t \in\left[T_{i}, T_{n}\right], g(t) \leq 0$. Hence, the optimal $t^{D}$ to the Model (I) is $T_{i}$, and this is Case 3.

If $\left.g(t)\right|_{t=T_{n}}<0$ and $\left.g(t)\right|_{t=T_{0}}>0$ and condition (4.33) is met, then from Theorem 4.2 we know that there exists a unique solution (denoted by $t^{D}$ ) to equation $g(t)=0$. From Theorem 4.2, we know that, for $t \in\left[T_{0}, t^{D}\right), g(t)>0$ and for $t \in\left(t^{D}, T_{n}\right], g(t)<0$. Hence, the optimal $t$ value of the Model (I) is $t^{D}$, and this is Case 4 . 


\subsection{Algorithms}

According to Theorem 4.4, we develop an algorithm for solving model (I). As far as model (II) is concerned, it may be deduced by analogy.

Step 1. Compute the values of $\left.g(t)\right|_{t=T_{0}}$ and $\left.g(t)\right|_{t=T_{n}}$, and compare them with zero, respectively. Go to Step 2.

Step 2. If $\left.g(t)\right|_{t=T_{0}} \leq 0$, then this is Case 1 in Theorem 4.4. Therefore, the optimal $t^{D}$ is $T_{0}$. Turn to Step 5.

If $\left.g(t)\right|_{t=T_{n}} \geq 0$, then this is Case 2 in the Theorem 4.4. Therefore, the optimal $t^{D}$ is $T_{n}$. Turn to Step 5.

If $\left.g(t)\right|_{t=T_{n}}<0$ and $\left.g(t)\right|_{t=T_{0}}>0$, then turn to Step 3.

Step 3. For $i(1 \leq i \leq n-1)$, check the signals of $\left.g(t)\right|_{t=T_{i}^{-}}$and $\left.g(t)\right|_{t=T_{i}}$ one by one. For certain $i$, if a non-positive number first appears between them, stop the check.

If a non-positive number occurs at $\left.g(t)\right|_{t=T_{i}}$ firstly, this is Case 3, and the optimal $t^{D}$ is $T_{i}$. Go to Step 5.

If a non-positive number occurs at $\left.g(t)\right|_{t=T_{i}^{-}}$firstly, this is Case 4 , turn to Step 4.

Step 4. A Golden section method or two-section method can be used to search the optimal solution to the equation $g(t)=0$ in the interval $\left(T_{i-1}, T_{i}\right)$. Let $t^{D}$ denote the optimal solution, go to Step 5.

Step 5. Compute the optimal $q^{D}$ to model (I) through (4.24), and end the algorithm.

The algorithm for solving model (II) is similar to that of the model (I) as mentioned above, so we skip it here.

\section{Supply Chain Coordination}

In a distributed supply chain, since the supply chain participants are independent entities; thus, decisions are made to maximize the decision maker's own profit. To some extent, the double marginalization (e.g., Spengler [41]) will take place, and this will cut down the profit of the whole supply chain. In order to improve supply chain efficiency, the supply chain participants can collaborate through a contract to get a win-win situation. The contract aligns the two self-interested parties, so their decentralized actions maximize the whole supply chain (Chen et al. [15]).

In apparel industries, the manufacturer usually uses buy-back contract to enable retailers to enlarge ordering quantity (such as Padmanabhan and Png [44]). In addition, since the crashing cost is existence, there is inconsistency for the optimal decision on the lead time from the retailer with that from the supply chain system. Hence, the manufacturer should share some of the crashing costs in order to motivate the retailer to obey the optimal decision on lead time from the supply chain channel.

In order to coordinate the supply chain, a three-parameter contract which combines buy-back and risk-sharing contract is developed in this paper.

Let $(b, w, \lambda)$ denote the three-parameter contract. Under such a contract, the manufacturer sells products at unit price of $w$ to the retailer at the start of the season and agrees to purchase $b$ ratio of left over units at the end of the selling season. $1-b$ ratio of left over units at the end of the selling season is salvaged by the retailer. Furthermore, $\lambda$ ratio 
of crashing cost is charged on the retailer, and $1-\lambda$ ratio of crashing cost is charged on the manufacturer.

In this scenario, the expected profit of the retailer is

$$
\Pi_{r}^{C}(q, t)=p E(\min (q, x))+(1-b) v E(q-x)^{+}+b w E(q-x)^{+}-w q-\lambda R(t) .
$$

The expected profit of the manufacturer is

$$
\Pi_{m}^{C}=(w-c) q+b(v-w) E(q-x)^{+}-(1-\lambda) R(t) .
$$

The expected profit of the whole supply chain is

$$
\Pi_{l}^{C}(q, t)=\Pi_{l}(q, t)=p E(\min (q, x))+v E(q-x)^{+}-c q-R(t) .
$$

where $q, t$ satisfies the constrains that $q>0, T_{0} \leq t \leq T_{n}$.

Under the cooperative circumstances with the three-parameter contract, in order to get a win-win situation, the optimal decision from the respective of the retailer (denoted by Model (III)) should be described as follows

Model (III):

$$
\begin{aligned}
\max _{q, t} & \Pi_{r}^{C}(q, t)=p E(\min (q, x))+(1-b) v E(q-x)^{+}+b w E(q-x)^{+}-w q-\lambda R(t), \\
\text { s.t. } & \Pi_{r}^{C}(q, t) \geq \Pi_{r}\left(q^{D}, t^{D}\right), \\
& \Pi_{m}^{C}(q, t) \geq \Pi_{m}\left(q^{D}, t^{D}\right), \\
& q>0, \quad T_{0} \leq t \leq T_{n} .
\end{aligned}
$$

Equations (5.4) and (5.5) are to assure that the profits of supply chain participants under coordination are no less than those under no coordination. Equations (5.4) and (5.5) also are called the incentive compatibility (IC) constraints.

The optimal solution to the Model (III) is denoted by $\left(q^{C}, t^{C}\right)$.

For the three-parameter contract $(b, w, \lambda)$, we have the following conclusion.

Theorem 5.1. If the three-parameter contract $(b, w, \lambda)$ meet the following conditions (5.6) to (5.8), then the supply chain will realize the supply chain coordination.

$$
\begin{aligned}
& \text { (1) } b=\frac{(p-v)(w-c)}{(p-c)(w-v)}, \\
& \text { (2) } \lambda=\frac{(p-w)}{(p-c)}, \\
& \text { (3) } c+(p-c) \frac{\Pi_{m}\left(q^{D}, t^{D}\right)}{\Pi_{l}\left(q^{I}, t^{I}\right)} \leq w \leq p-(p-c) \frac{\Pi_{r}\left(q^{D}, t^{D}\right)}{\Pi_{l}\left(q^{I}, t^{I}\right)} \text {. }
\end{aligned}
$$


Proof. It is obvious that $0<\lambda<1$ and $0<b<1$.

Since $\min (q, x)=q-(q-x)^{+}$, we get

$$
E(\min (q, x))=E(q-(q-x))=q-E(q-x)^{+}
$$

Substituting (5.9) into (5.1) and (5.3), we get

$$
\begin{gathered}
\Pi_{r}^{C}(q, t)=(p-w) q+(b(w-v)-(p-v)) E(q-x)^{+}-\lambda R(t), \\
\Pi_{l}^{C}(q, t)=\Pi_{l}(q, t)=(p-c) q+(p-v) E(q-x)^{+}-R(t) .
\end{gathered}
$$

Substituting (5.6) and (5.7) into (5.10) and simplifying it, we can get

$$
\Pi_{r}^{C}(q, t)=\lambda\left((p-c) q+(p-v) E(q-x)^{+}-R(t)\right)=\lambda \Pi_{l}^{C}(q, t) .
$$

Substituting (5.6) and (5.7) into (5.2) and simplifying it, we have

$$
\Pi_{m}^{C}=(1-\lambda) \Pi_{l}^{C}(q, t) .
$$

Because $\lambda$ is a constant, given parameters $p, w, c$ from (5.12), it is obvious that the optimal decision from the whole supply chain is the same as the optimal decision from the retailer. Here, we know that

$$
\left(q^{C}, t^{C}\right)=\left(q^{I}, t^{I}\right)
$$

Substituting (5.12) and (5.13) into (5.4) and (5.5); respectively, we can get

$$
\begin{gathered}
\lambda \Pi_{l}\left(q^{C}, t^{C}\right) \geq \Pi_{r}\left(q^{D}, t^{D}\right), \\
(1-\lambda) \Pi_{l}\left(q^{C}, t^{C}\right) \geq \Pi_{m}\left(q^{D}, t^{D}\right) .
\end{gathered}
$$

Substituting (5.7) into (5.15) and using (5.14), we can get (5.8).

For a contract to be implementable, it is necessary that the contract can arbitrarily allocate the supply-chain profit between the retailer and supplier (see, e.g., Chen et al. [15], Cachon [43]). As for this question, we have the following conclusion.

Theorem 5.2. The profit of the whole supply chain system is divided into two parts by the threeparameter contract $(b, w, \lambda)$, and each part of the profit embodies the supply chain participants' valueadded capacities. The three-parameter contract can arbitrarily allocate the profit of the supply chain between the manufacturer and the retailer by tuning the value of $w$ in a feasible range determined by the condition (5.8). 
Table 1: Lead time data.

\begin{tabular}{lccc}
\hline $\begin{array}{l}\text { Component element of } \\
\text { lead time }(i)\end{array}$ & Regular time $b_{i}$ (day) & Minimum time $a_{i}$ (day) & Crash costs $o_{i}(\$ /$ day) \\
\hline 1 & 50 & 30 & $1 * \delta$ \\
2 & 40 & 24 & $2 * \delta$ \\
3 & 40 & 20 & $4 * \delta$ \\
4 & 40 & 26 & $6 * \delta$ \\
5 & 30 & 20 & $10 * \delta$ \\
\hline
\end{tabular}

Proof. Substituting (5.7) into (5.12) and (5.13), we can get

$$
\begin{aligned}
& \Pi_{r}\left(q^{C}, t^{C}\right)=\frac{p-w}{p-c} \Pi_{l}\left(q^{I}, t^{I}\right), \\
& \Pi_{m}\left(q^{C}, t^{C}\right)=\frac{w-c}{p-c} \Pi_{l}\left(q^{I}, t^{I}\right) .
\end{aligned}
$$

Here, $p-c$ is the profit for each product sold in the supply chain, and it can represent the value-added capacity of the supply chain; $w-c$ and $p-w$ represent the value-added capacity of the manufacturer and the retailer, respectively.

If the wholesale price changes from $w$ to $w+\Delta w$ in a feasible range determined by the condition (5.8), then the profit of the manufacturer increases $(\Delta w / p-c) \Pi_{l}\left(q^{I}, t^{I}\right)$, and the profit of the retailer decreases $(\Delta w / p-c) \Pi_{l}\left(q^{I}, t^{I}\right)$. Thus, the three-parameter contract $(b, w, \lambda)$ can flexibly allocate the profits among the supply chain.

\section{Numerical Analysis}

To illustrate the above models and algorithms, we consider a supply chain: the retail price $p=20 \$ /$ unit, the wholesale price $w_{0}=10 \$ /$ unit, the marginal production cost $c=5 \$ /$ unit, the residual value of products unsold at the end of the selling season $v=3 \$ /$ unit. Lead time consists of $n=5$ components is shown in Table 1 . Here $\delta$ is an adjustable coefficient which represents a certain crashing cost. In arbitrary lead time $t\left(T_{0} \leq t \leq T_{n}\right)$, we use function $s(t)=\alpha e^{\beta t}(\alpha=140, \beta=0.0035)$ to formulate the relationship between the forecast error of expected demand's distribution and the lead time. The parameters of demand distribution are $\mu=2000$ units, $\tau=200$ units.

Using the algorithms introduced in Section 4.3, we can solve the Model (I) and Model (II). For some different values of $\delta$, such as $0.1,0.5,1,2,5,6,8$, and 10 , these solutions and correspondent profits of the supply chain participants and the whole supply chain are illustrated in Table 2.

As shown in Table 2, the optimal ordering quantity and lead time under the centralized decision-making scenario are different from that under decentralized decision-making scenario. From the respective of the whole supply chain, if a unit of a product is sold, it can bring $p-c=15 \$$ profit to the supply chain; and if a unit of product is overstocked, it can lead to $c-v=2 \$$ loss against the supply chain. Comparatively, from the respective of the retailer, if a unit of a product is sold, it can bring in $p-w_{0}=10 \$$ profit for the retailer and if a unit of product is overstocked, it can lead to $w_{0}-v=7 \$$ loss against the retailer. 
Table 2: The optimal solution to Model (I) and (II) with different values of $\delta$.

\begin{tabular}{|c|c|c|c|c|c|c|c|c|c|c|c|}
\hline \multirow{3}{*}{$\delta$} & \multicolumn{5}{|c|}{$\begin{array}{l}\text { Decentralized decision-making model } \\
\text { Model (I) }\end{array}$} & \multicolumn{5}{|c|}{$\begin{array}{c}\text { Centralized decision-making model } \\
\text { Model (II) }\end{array}$} & \multirow{3}{*}{$\Delta_{l}$} \\
\hline & \multicolumn{2}{|c|}{ Optimal solution } & \multicolumn{3}{|c|}{ Profit allocation } & \multicolumn{2}{|c|}{ Optimal solution } & \multicolumn{3}{|c|}{ Profit allocation } & \\
\hline & $t^{D}$ & $q^{D}$ & $\Pi_{r}\left(q^{D}, t^{D}\right)$ & $\Pi_{m}$ & $\Pi_{l}\left(q^{D}, t^{D}\right)$ & $t^{C}$ & $q^{C}$ & $\Pi_{r}\left(q^{I}, t^{I}\right)$ & $\Pi_{m}$ & $\Pi_{l}\left(q^{I}, t^{I}\right)$ & \\
\hline 0.10 & 120.00 & 057.6 & 18260 & 10288 & 28548 & 120.00 & 2306.4 & 17570 & 11532 & 29103 & 555 \\
\hline 0.50 & 122.58 & 2058.0 & 18134 & 10290 & 28424 & 144.00 & 2328.5 & 17363 & 11643 & 29006 & 582 \\
\hline 1.00 & 144.00 & 2061.7 & 18037 & 10309 & 28345 & 164.00 & 2348.2 & 17223 & 11741 & 28964 & 619 \\
\hline 2.00 & 164.00 & 2065.4 & 17955 & 10327 & 28282 & 180.00 & 2364.7 & 17106 & 11824 & 28929 & 647 \\
\hline 5.00 & 180.00 & 2068.5 & 17867 & 10343 & 28210 & 200.00 & 2386.6 & 16975 & 11933 & 28908 & 698 \\
\hline 6.00 & 185.15 & 2069.6 & 17847 & 10348 & 28195 & 200.00 & 2386.6 & 16975 & 11933 & 28908 & 713 \\
\hline 8.00 & 200.00 & 2072.6 & 17845 & 10363 & 28208 & 200.00 & 2386.6 & 16975 & 11933 & 28908 & 700 \\
\hline 10.00 & 200.00 & 2072.6 & 17845 & 10363 & 28208 & 200.00 & 2386.6 & 16975 & 11933 & 28908 & 700 \\
\hline
\end{tabular}

It is obvious that the risk for the retailer to order more is much higher than that for the supply chain. Therefore, the retailer's decision on order quantities tends to be conservative.

As far as lead time is concerned, the retailer can benefit from the demand forecast updates by reducing the lead time while it can bring more crashing cost to the whole supply chain. Thus, the decentralized decision from the retailer cannot be consistent with that of the centralized decision from the supply chain. Column 1 of Table $2, \Delta_{l}$, represents the difference of profits between the two decision-making scenarios. We can see that the decentralized decision making results in a suboptimal solution to the whole supply chain.

Hence, in order to coordinate the supply chain, risk should be distributed and shared among supply chain partners. This idea is embodied in the three-parameters contract proposed in Section 5. It makes the manufacturer and the retailer share the risk of the overstock and the crashing cost in order to maximize the profit of the whole supply chain and get a win-win situation. The parameters in the contract are developed in Table 3.

For fixed $\delta$, using (5.8) and the data in Table 2, we can obtain the range of $w$. For example, in order to get supply chain coordination, the $w$ must range from 10.3025 to 10.5884 in the case of $\delta=0.1$.

For fixed $\delta=0.1$, let $w$ vary in the range of 10.3025 to 10.5884 , then we can calculate the other two parameters in the contract with different $w$. Here, we can see that it is the value of $w$ that determines the supply chain's profit allocation. To determine the value of $w$ depends on the supply chain participants' ability to bargain.

In Table $3, \Pi_{r}^{C}, \Pi_{m}^{C}$, and $\Pi_{l}^{C}$ denote the profits of supply chain participants and the whole supply chain system with coordination $\Delta_{r}$ and $\Delta_{m}$ denote the profit increments of the supply chain participants with coordination and $\Delta_{r} / \Delta_{l}$ and $\Delta_{m} / \Delta_{l}$ denote the ratios of the profit increments shared among the supply chain.

From Table 3, we can see that the three-parameter contract is effective and flexible to coordinate the supply chain.

\section{Conclusions and Future Research}

In this paper, we investigate two questions for a short-life-cycle-product supply chain, in which the forecast error of expected demand is a log-linear function of lead time, and crashing cost is a stepwise linear function of the lead time. Under this assumption and accounting 
Table 3: Contract and supply chain coordination.

\begin{tabular}{|c|c|c|c|c|c|c|c|c|c|c|}
\hline \multicolumn{3}{|c|}{ Contract parameters } & \multicolumn{3}{|c|}{ Retailer } & \multicolumn{3}{|c|}{ Manufacturer } & \multicolumn{2}{|c|}{ Supply chain } \\
\hline$w$ & $b$ & $\lambda$ & $\Pi_{r}^{C}$ & $\Delta_{r}$ & $\Delta_{r} / \Delta_{l}$ & $\Pi_{m}^{C}$ & $\Delta_{m}$ & $\Delta_{m} / \Delta_{l}$ & $\Pi_{l}^{C}$ & $\Delta_{l}$ \\
\hline \multicolumn{11}{|c|}{$\delta=0.1,\left(q^{C}, t^{C}\right)=\left(q^{I}, t^{I}\right)=(2306.4,120), 10.3025 \leq w \leq 10.5884$} \\
\hline 10.3025 & 0.8229 & 0.6465 & 18815 & 555 & $100 \%$ & 10288 & 0 & $0 \%$ & 29103 & 555 \\
\hline 10.4 & 0.827 & 0.64 & 18626 & 366 & $66 \%$ & 10477 & 189 & $34 \%$ & 29103 & 555 \\
\hline 10.5 & 0.8311 & 0.6333 & 18432 & 172 & $31 \%$ & 10671 & 383 & $69 \%$ & 29103 & 555 \\
\hline 10.5884 & 0.8346 & 0.6274 & 18260 & 0 & $0 \%$ & 10843 & 555 & $100 \%$ & 29103 & 555 \\
\hline \multicolumn{11}{|c|}{$\delta=0.5,\left(q^{C}, t^{C}\right)=\left(q^{I}, t^{I}\right)=(2328.5,144), 10.3213 \leq w \leq 10.6223$} \\
\hline 10.3213 & 0.8237 & 0.6452 & 18716 & 582 & $100 \%$ & 10290 & 0 & $0 \%$ & 29006 & 582 \\
\hline 10.4 & 0.827 & 0.64 & 18564 & 430 & $74 \%$ & 10442 & 152 & $26 \%$ & 29006 & 582 \\
\hline 10.5 & 0.8311 & 0.6333 & 18370 & 237 & $41 \%$ & 10636 & 345 & $59 \%$ & 29006 & 582 \\
\hline 10.6 & 0.8351 & 0.6267 & 18177 & 43 & $7 \%$ & 10829 & 539 & $93 \%$ & 29006 & 582 \\
\hline 10.6223 & 0.836 & 0.6252 & 18134 & 0 & $0 \%$ & 10872 & 582 & $100 \%$ & 29006 & 582 \\
\hline \multicolumn{11}{|c|}{$\delta=1,\left(q^{C}, t^{C}\right)=\left(q^{I}, t^{I}\right)=(2348.2,164), 10.3387 \leq w \leq 10.6591$} \\
\hline 10.4 & 0.827 & 0.64 & 18537 & 500 & $81 \%$ & 10427 & 118 & $19 \%$ & 28964 & 619 \\
\hline 10.5 & 0.8311 & 0.6333 & 18344 & 307 & $50 \%$ & 10620 & 311 & $50 \%$ & 28964 & 619 \\
\hline 10.6 & 0.8351 & 0.6267 & 18151 & 114 & $18 \%$ & 10813 & 505 & $82 \%$ & 28964 & 619 \\
\hline \multicolumn{11}{|c|}{$\delta=2,\left(q^{C}, t^{C}\right)=\left(q^{I}, t^{I}\right)=(2364.7,180), 10.3387 \leq w \leq 10.6591$} \\
\hline 10.4 & 0.827 & 0.64 & 18515 & 559 & $86 \%$ & 10414 & 87 & $14 \%$ & 28929 & 647 \\
\hline 10.5 & 0.8311 & 0.6333 & 18322 & 366 & $57 \%$ & 10607 & 280 & $43 \%$ & 28929 & 647 \\
\hline 10.6 & 0.8351 & 0.6267 & 18129 & 174 & $27 \%$ & 10800 & 473 & $73 \%$ & 28929 & 647 \\
\hline \multicolumn{11}{|c|}{$\delta=5,\left(q^{C}, t^{C}\right)=\left(q^{I}, t^{I}\right)=(2386.6,200), 10.7290 \leq w \leq 10.3667$} \\
\hline 10.4 & 0.827 & 0.64 & 18501 & 634 & $91 \%$ & 10407 & 64 & $9 \%$ & 28908 & 698 \\
\hline 10.5 & 0.8311 & 0.6333 & 18308 & 441 & $63 \%$ & 10600 & 257 & $37 \%$ & 28908 & 698 \\
\hline 10.6 & 0.8351 & 0.6267 & 18116 & 249 & $36 \%$ & 10792 & 450 & $64 \%$ & 28908 & 698 \\
\hline \multicolumn{11}{|c|}{$\delta=6,\left(q^{C}, t^{C}\right)=\left(q^{I}, t^{I}\right)=(2386.6,200), 10.369 \leq w \leq 10.7392$} \\
\hline 10.4 & 0.827 & 0.64 & 18501 & 654 & $92 \%$ & 10407 & 59 & $8 \%$ & 28908 & 713 \\
\hline 10.5 & 0.8311 & 0.6333 & 18308 & 461 & $65 \%$ & 10600 & 252 & $35 \%$ & 28908 & 713 \\
\hline 10.6 & 0.8351 & 0.6267 & 18116 & 268 & $38 \%$ & 10792 & 445 & $62 \%$ & 28908 & 713 \\
\hline 10.7 & 0.839 & 0.62 & 17923 & 76 & $11 \%$ & 10985 & 637 & $89 \%$ & 28908 & 713 \\
\hline \multicolumn{11}{|c|}{$\delta=8,\left(q^{C}, t^{C}\right)=\left(q^{I}, t^{I}\right)=(2386.6,200), 10.3773 \leq w \leq 10.7403$} \\
\hline 10.4 & 0.827 & 0.64 & 18501 & 656 & $94 \%$ & 10407 & 44 & $6 \%$ & 28908 & 700 \\
\hline 10.5 & 0.8311 & 0.6333 & 18308 & 463 & $66 \%$ & 10600 & 236 & $34 \%$ & 28908 & 700 \\
\hline 10.6 & 0.8351 & 0.6267 & 18116 & 270 & $39 \%$ & 10792 & 429 & $61 \%$ & 28908 & 700 \\
\hline 10.7 & 0.839 & 0.62 & 17923 & 78 & $11 \%$ & 10985 & 622 & $89 \%$ & 28908 & 700 \\
\hline \multicolumn{11}{|c|}{$\delta=10,\left(q^{C}, t^{C}\right)=\left(q^{I}, t^{I}\right)=(2386.6,200), 10.3773 \leq w \leq 10.7403$} \\
\hline 10.4 & 0.827 & 0.64 & 18501 & 656 & $94 \%$ & 10407 & 44 & $6 \%$ & 28908 & 700 \\
\hline 10.5 & 0.8311 & 0.6333 & 18308 & 463 & $66 \%$ & 10600 & 236 & $34 \%$ & 28908 & 700 \\
\hline 10.6 & 0.8351 & 0.6267 & 18116 & 270 & $39 \%$ & 10792 & 429 & $61 \%$ & 28908 & 700 \\
\hline 10.7 & 0.839 & 0.62 & 17923 & 78 & $11 \%$ & 10985 & 622 & $89 \%$ & 28908 & 700 \\
\hline
\end{tabular}

for the considerations performed for the single-buyer-single-vendor supply chain, we model decisions on lead time and ordering quantity in a decentralized decision-making scenario and a centralized decision-making scenario, respectively. Then, the attributes and existence of the optimal solutions to the models are analyzed. Based on the analysis, the algorithms to solve the models are developed. To validate the algorithms and models, a numerical example 
Table 4: Values of $t, s(t)$ and $y$.

\begin{tabular}{lccccc}
\hline$t$ (month) & 12 & 9 & 6 & 3 & 0 \\
\hline$s(t) \%$ & 40 & 23 & 19 & 15 & 10 \\
\hline$y=\ln s(t)$ & 3.6889 & 3.1355 & 2.9444 & 2.7081 & 2.3026 \\
\hline
\end{tabular}

is presented. The numerical result shows that the algorithms are effective. Furthermore, in order to alleviate the double margin in the decentralized decision-making scenario, a threeparameter supply chain contract is proposed to coordinate the supply chain. Through the three-parameter contract, the whole supply chain's profit is divided into two parts. Each of them represents the single supply chain participant's value-added capacities. The contract can arbitrarily allocate the supply chain profit between the manufacturer and the retailer by tuning the value of parameters. For this reason, it is easy for practitioners to adopt in practical.

In this study, only single product and single ordering are considered. Moreover, multiple-product supply chain is universal in practice and, with shorter lead time, more than one order can be placed. Therefore, it would be interesting to study multiple products' scenario or multiple-order policies scenario in the future research.

\section{Appendix}

\section{Fitting a Log-Linear Relationship between $s(t)$ and $t$}

As shown in Figure 2, corresponding to $t=0,3,6,9,12$ (month), the forecast error of expected demand is $s(t)=10,15,19,23,40$ (\% percentage of expected demand), respectively. Let $y=$ $\ln s(t)$, then the values of $y$ (together with $t$ and $s(t)$ ) are shown in Table 4.

Computing the coefficient between $y$ and $t$ (using the CORRCOEF function in the Statistics tool box for Matlab), we can get the following.

The coefficient matrix of $y$ and $t$ is $R=\left[\begin{array}{lll}1.0000 & 0.9839 \\ 0.9839 & 1.0000\end{array}\right]$, and the $P$-value matrix is $P=$ $\left[\begin{array}{lll}1.0000 & 0.0025 \\ 0.0025 & 1.0000\end{array}\right]$.

The result $(0.0025 \ll 0.05)$ shows that there exists a significant linear correlation between $y=\ln s(t)$ and $t$ at a given confidence level of $95 \%$. This means that $t$ and $\ln s(t)$ can be written as

$$
\ln s(t)=a+b t
$$

That is, $s(t)$ is log-linear function of $t$.

Hence, denoting $\alpha=e^{a}$ and $\beta=b, s(t)$ may be written as

$$
s(t)=\alpha e^{\beta t} .
$$

\section{Acknowledgments}

This work is supported by the Natural Science Foundation of China under Grant no. 70872047. The authors gratefully acknowledge the helpful comments and suggestions of the editor and the anonymous reviewers which led to a substantial improvement of this paper. The authors also thank Yiliu (Paul) Tu, the professor of The Schulich School of Engineering, 
University of Calgary, and Ding Zhang, the professor of the School of Business, the State University of New York at Oswego, for their helpful works which have contributed to improving the readability of the paper.

\section{References}

[1] B. Lowson, R. King, and A. Hunter, Quick Response-Managing the Supply Chain to Meet Consumer Demand, John Wiley \& Sons, New York, NY, USA, 1999.

[2] R. J. Tersine and E. A. Hummingbird, "Lead-time reduction: the search for competitive advantage," International Journal of Operations and Production Management, vol. 15, no. 2, pp. 8-18, 1995.

[3] S. S. Rohr and H. L. Correa, "Time-based competitiveness in Brazil: whys and hows," International Journal of Operations and Production Management, vol. 18, no. 3, pp. 233-245, 1998.

[4] M. Perry, A. S. Sohal, and P. Rumpf, "Quick response supply chain alliances in the Australian textiles, clothing and footwear industry," International Journal of Production Economics, vol. 62, no. 1, pp. 119$132,1999$.

[5] A. V. Iyer and M. E. Bergen, "Quick response in manufacturer-retailer channels," Management Science, vol. 43 , no. 4 , pp. 559-570, 1997.

[6] J. Wu, "Quantity flexibility contracts under Bayesian updating," Computers and Operations Research, vol. 32, no. 5, pp. 1267-1288, 2005.

[7] T.-M. Choi, "Quick response in fashion supply chains with dual information updating," Journal of Industrial and Management Optimization, vol. 2, no. 3, pp. 255-268, 2006.

[8] T.-M. Choi, D. Li, and H. Yan, “Quick response policy with Bayesian information updates,” European Journal of Operational Research, vol. 170, no. 3, pp. 788-808, 2006.

[9] M. Fisher and A. Raman, "Reducing the cost of demand uncertainty through accurate response to early sales," Operations Research, vol. 44, no. 1, pp. 87-99, 1996.

[10] H. Gurnani and C. S. Tang, "Note: optimal ordering decisions with uncertain cost and demand forecast updating," Management Science, vol. 45, no. 10, pp. 1456-1462, 1999.

[11] K. L. Donohue, "Efficient supply contract for fashion goods with forecast updating and two production modes," Management Science, vol. 46, no. 11, pp. 1397-1411, 2000.

[12] S. P. Sethi, H. Yan, H. Zhang, and J. Zhou, "Information updated supply chain with service-level constraints," Journal of Industrial and Management Optimization, vol. 1, no. 4, pp. 513-531, 2005.

[13] T. M. Choi and D. Li, "Optimal two-stage ordering policy with Bayesian information updating," Journal of the Operational Research Society, vol. 54, no. 8, pp. 846-859, 2003.

[14] T. M. Choi, "Pre-season stocking and pricing decisions for fashion retailers with multiple information updating," International Journal of Production Economics, vol. 106, no. 1, pp. 146-170, 2007.

[15] H. Chen, J. Chen, and Y. Chen, "A coordination mechanism for a supply chain with demand information updating," International Journal of Production Economics, vol. 103, no. 1, pp. 347-361, 2006.

[16] H. Chen, Y. Chen, C. H. Chiu, T. M. Choi, and S. Sethi, "Coordination mechanism for the supply chain with leadtime consideration and price-dependent demand," European Journal of Operational Research, vol. 203, no. 1, pp. 70-80, 2010.

[17] S. P. Sethi, H. Yan, and H. Zhang, "Peeling layers of an onion: inventory model with multiple delivery modes and forecast updates," Journal of Optimization Theory and Applications, vol. 108, no. 2, pp. 253281, 2001.

[18] S. P. Sethi, H. Yan, and H. Zhang, "Inventory models with fixed costs, forecast updates, and two delivery modes," Operations Research, vol. 51, no. 2, pp. 321-328, 2003.

[19] S. P. Sethi, H. Yan, and H. Zhang, "Quantity flexibility contracts: optimal decisions with information updates," Decision Sciences, vol. 35, no. 4, pp. 691-712, 2004.

[20] T.-M. Choi, D. Li, and H. Yan, "Optimal single ordering policy with multiple delivery modes and Bayesian information updates," Computers \& Operations Research, vol. 31, no. 12, pp. 1965-1984, 2004.

[21] C.J. Liao and C. H. Shyu, "An analytical determination of lead time with normal demand," International Journal of Operations and Production Management, vol. 11, no. 9, pp. 72-77, 1991.

[22] M. Ben-Daya and A. Raouf, "Inventory models involving lead time as a decision variable," Journal of the Operational Research Society, vol. 45, no. 5, pp. 579-582, 1994.

[23] M. Ben-Daya and M. Hariga, "Integrated single vendor single buyer model with stochastic demand and variable lead time," International Journal of Production Economics, vol. 92, no. 1, pp. 75-80, 2004. 
[24] L. Y. Ouyang, N. C. Yeh, and K. S. Wu, "Mixture inventory model with backorders and lost sales for variable lead time," Journal of the Operational Research Society, vol. 47, no. 6, pp. 829-832, 1996.

[25] L.-Y. Ouyang and H.-C. Chang, "Lot size reorder point inventory model with controllable lead time and set-up cost," International Journal of Systems Science, vol. 33, no. 8, pp. 635-642, 2002.

[26] L. Y. Ouyang, K. S. Wu, and C. H. Ho, "Integrated vendor-buyer cooperative models with stochastic demand in controllable lead time," International Journal of Production Economics, vol. 92, no. 3, pp. 255-266, 2004.

[27] L. Y. Ouyang, K. S. Wu, and C. H. Ho, "An integrated vendor-buyer inventory model with quality improvement and lead time reduction," International Journal of Production Economics, vol. 108, no. 1-2, pp. 349-358, 2007.

[28] I. Moon and S. Choi, "A note on lead time and distributional assumptions in continuous review inventory models," Computers \& Operations Research, vol. 25, no. 11, pp. 1007-1012, 1998.

[29] I. K. Moon and B. C. Cha, "A continuous review inventory model with the controllable production rate of the manufacturer," International Transactions in Operational Research, vol. 12, no. 2, pp. 247-258, 2005.

[30] M. Hariga and M. Ben-Daya, "Some stochastic inventory models with deterministic variable lead time," European Journal of Operational Research, vol. 113, no. 1, pp. 42-51, 1999.

[31] M. A. Hariga, "Setup cost reduction in (Q, r) policy with lot size, setup time and lead-time interactions," Journal of the Operational Research Society, vol. 51, no. 11, pp. 1340-1345, 2000.

[32] J. C. H. Pan and J. S. Yang, "A study of an integrated inventory with controllable lead time," International Journal of Production Research, vol. 40, no. 5, pp. 1263-1273, 2002.

[33] C. T. Chang and S. C. Chang, "On the inventory model with variable lead time and price-quantity discount," Journal of the Operational Research Society, vol. 52, no. 10, pp. 1151-1158, 2001.

[34] H.-C. Chang, J.-S. Yao, and L.-Y. Ouyang, "Fuzzy mixture inventory model with variable lead-time based on probabilistic fuzzy set and triangular fuzzy number," Mathematical and Computer Modelling, vol. 39, no. 2-3, pp. 287-304, 2004.

[35] H.-C. Chang, J.-S. Yao, and L.-Y. Ouyang, "Fuzzy mixture inventory model involving fuzzy random variable lead time demand and fuzzy total demand," European Journal of Operational Research, vol. 169, no. 1, pp. 65-80, 2006.

[36] P. Chu, K.-L. Yang, and P. S. Chen, "Improved inventory models with service level and lead time," Computers \& Operations Research, vol. 32, no. 2, pp. 285-296, 2005.

[37] W. C. Lee, J. W. Wu, and C. L. Lei, “Optimal inventory policy involving back-order discounts and variable lead time demand," International Journal of Advanced Manufacturing Technology, vol. 34, no. 9-10, pp. 958-967, 2007.

[38] Y. J. Lin, "A periodic review inventory model involving fuzzy expected demand short and fuzzy backorder rate," Computers and Industrial Engineering, vol. 54, no. 3, pp. 666-676, 2008.

[39] J.-W. Wu, W.-C. Lee, and C.-L. Lei, "Optimal inventory policy involving ordering cost reduction, back-order discounts, and variable lead time demand by minimax criterion," Mathematical Problems in Engineering, vol. 2009, Article ID 928932, 19 pages, 2009.

[40] J. K. Jha and K. Shanker, "Two-echelon supply chain inventory model with controllable lead time and service level constraint," Computers and Industrial Engineering, vol. 57, no. 3, pp. 1096-1104, 2009.

[41] J. Spengler, “Vertical integration and antitrust policy,” Journal of Political Economy, vol. 58, no. 4, pp. 347-352, 1950.

[42] J.-C. Hennet and Y. Arda, "Supply chain coordination: a game-theory approach," Engineering Applications of Artificial Intelligence, vol. 21, no. 3, pp. 399-405, 2008.

[43] G. P. Cachon, "Supply chain coordination with contracts," in Handbooks in Operations Research and Management Science, S. Graves and T. de Kok, Eds., pp. 229-340, North Holland Press, 2003.

[44] V. Padmanabhan and I. P. L. Png, "Manufacturer's returns policies and retail competition," Marketing Science, vol. 16, no. 1, pp. 81-94, 1997.

[45] A. A. Tsay, "The quantity flexibility contract and supplier-customer incentives," Management Science, vol. 45, no. 10, pp. 1339-1358, 1999.

[46] G. P. Cachon and M. A. Lariviere, "Supply chain coordination with revenue-sharing contracts: strengths and limitations," Management Science, vol. 51, no. 1, pp. 30-44, 2005. 
[47] M. A. Lariviere and E. L. Porteus, "Selling to the newsvendor: analysis of price-only contracts," Manufacturing and Service Operations Management, vol. 3, no. 4, pp. 293-305, 2001.

[48] Arshinder, A. Kanda, and S. G. Deshmukh, "Supply chain coordination: perspectives, empirical studies and research directions," International Journal of Production Economics, vol. 115, no. 2, pp. 316335, 2008.

[49] J. D. Blackburn, Time-Based Competition: The Next Battleground in American Manufacturing, Business one Irwin, Homewood, Ill, USA, 1991. 


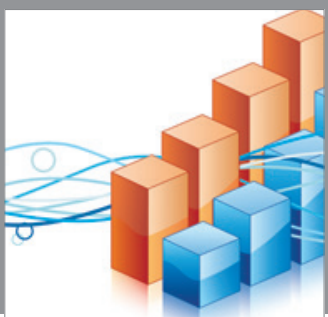

Advances in

Operations Research

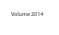

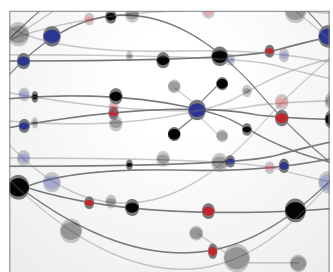

\section{The Scientific} World Journal
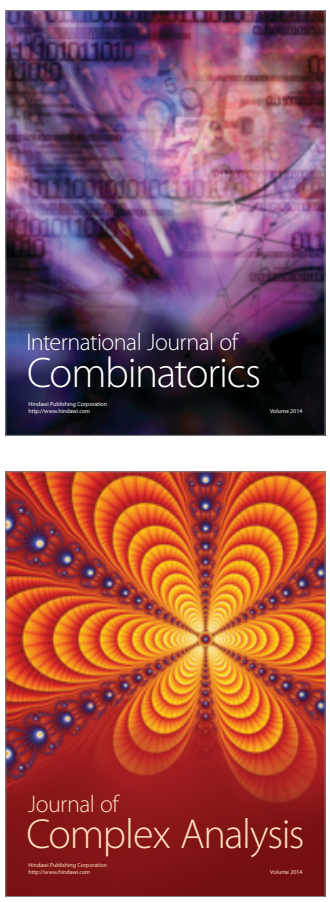

International Journal of

Mathematics and

Mathematical

Sciences
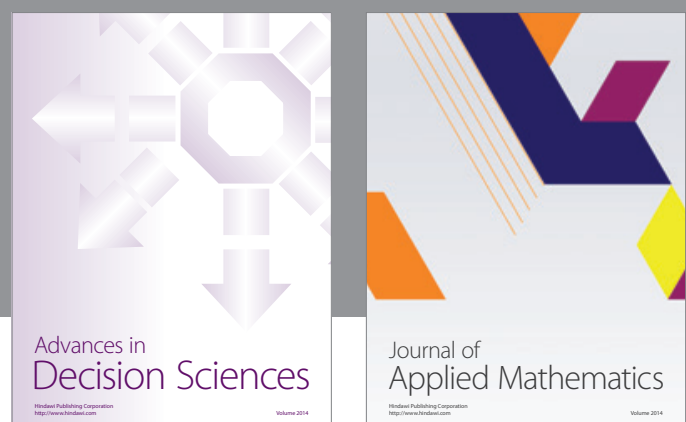

Journal of

Applied Mathematics
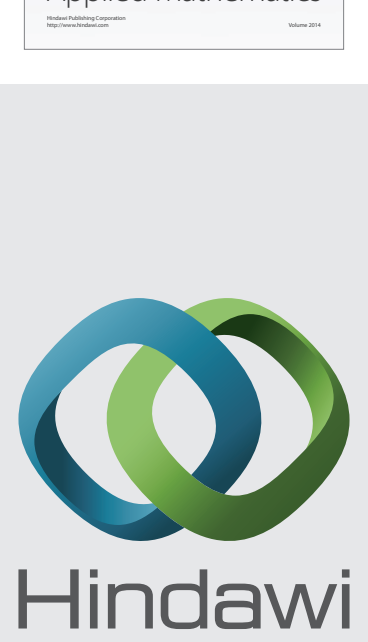

Submit your manuscripts at http://www.hindawi.com
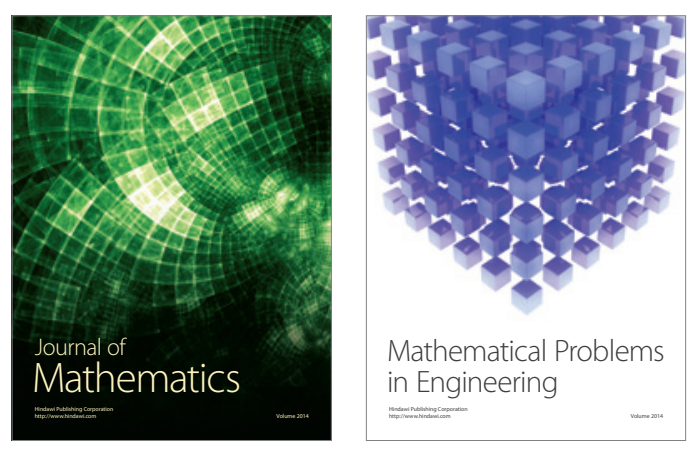

Mathematical Problems in Engineering
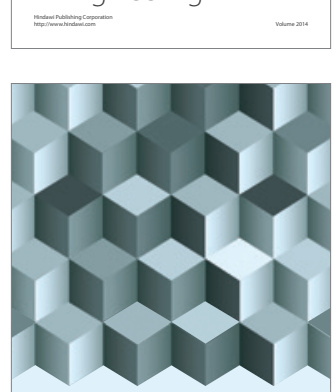

Journal of

Function Spaces
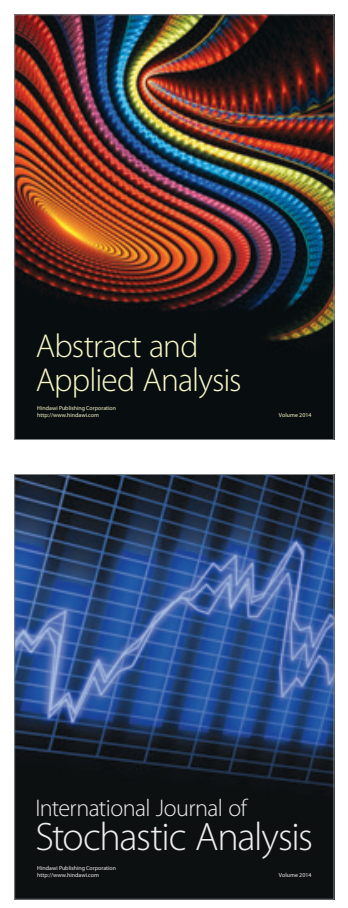

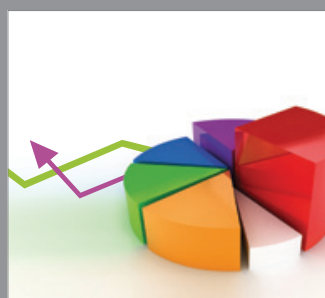

ournal of

Probability and Statistics

Promensencen
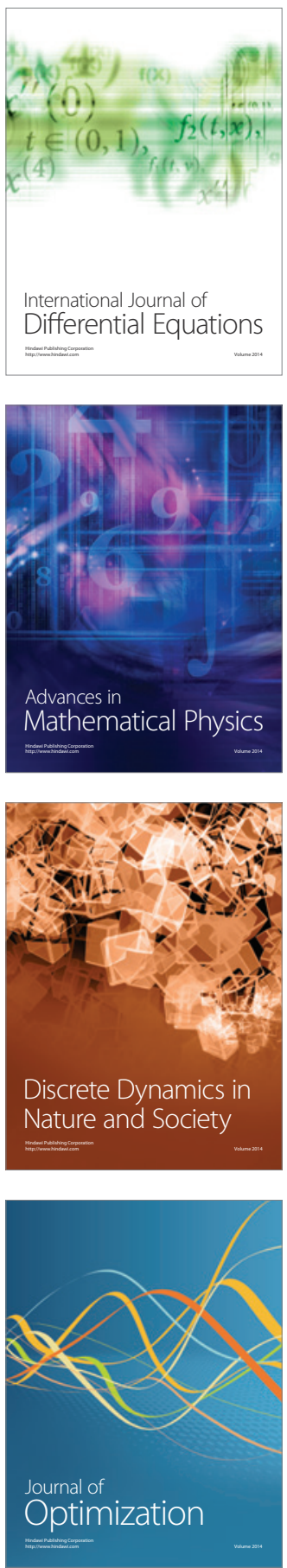